\title{
Influences of Online Sports Information on College Students' Sports Consciousness and Behavior
}

\author{
Rao Jianbo \\ Wuchang Institute of Technology 430065
}

\begin{abstract}
With the rapid development of network information technology, network media has gradually brought about the development of sports media industry online. Modern sports information is more transmitted through online media. At present, sports information in the network has a great influence on college students' sports awareness and behavior. These students can quickly obtain sports information by using network media, which shows the timeliness and convenience of getting sports information. Through the analysis of online sports information and relationship between network media and sports information, the dissemination of sports information online can help college students to establish the correct outlook on life and values, enriching students' mental life and daily sports activities. However, the flooding spread of sports information can also lead to some negative effects. Based on this, this paper makes an indepth analysis of the impact of online sports information on college students' sports consciousness and behavior.
\end{abstract}

Keywords-Information online; College students; Sports consciousness; Behavior

\section{INTRODUCTION}

With the rapid development of Internet information technology and the wide spread of modern sports culture [1], the online dissemination of sports information has become a main method for sports information to spread. The internet has gradually permeated college campuses and become an integral part of contemporary college students' study and life. The most important activity for students in entertainment is surfing the Internet and browsing all kinds of network information. The internet is a new medium with more exposure to college students and necessary for the modern society. Meanwhile, the network and multimedia technology can also be used in college physical education teaching. The implementation of physical education teaching through the network and multimedia can pass theoretical knowledge and practical skills in a more visual form to students to deepen students' understanding and mastery. College students' sports awareness and behavior mainly refers to their sports lifestyle, namely a special awareness and behavior in order to meet all kinds of sports life, which is a visual representation of sports values [2].

At present, the internet is full of all kinds of sports information, which mainly includes videos of sports events, sports performances and physical education. These sports information can meet college students' sports love and needs, and in the guidance of these sports information, college students can learn lots of sports information and related

\section{Author Profile:}

Rao Jianbo, a male from Han ethnic group, was born in January, 1982 in Wuhan, Hubei Province. Graduated from Wuhan Institute of Physical

Education in 2005, he is a lecturer on Science of Physical Education and Training at Wuchang Institute of Technology. information that they do not have in class. Sports information online closer to college students' sports awareness and behavior can satisfy the needs of college students' sports life, and to a certain extent, enrich college students' extracurricular activities, which has a positive impact on college students' sports awareness and behavior, helping college students to establish correct values of sports as well as laying a good foundation for growth of physical and mental health for students. Therefore, it is necessary to analyze the impact of online sports information on college students' sports awareness and behavior from a deeper perspective, in order to better guide these students to develop the correct sports awareness and behavior.

\section{AN OVERVIEW OF ONLINE SPORTS INFORMATION}

\section{A. Characteristics of Online Sports Information}

With the rapid development of network information technology, the competition in the network market becomes more and more fierce. The speed of online sports information dissemination is faster, the information more comprehensive, and communication with each other can be realized on the network platform. Therefore, the online sports information has become a main component of the current sports media. It is because online sports information has such several characteristics that it exerts a great effect on college students' sports awareness and behavior, which is mainly manifested in the following aspects. First, online sports information with timeliness and advancement have a great attraction for college students, meeting their curiosity. Second, online sports information involves a large amount of information including comprehensive sports information, which enables college students to understand all aspects of domestic and foreign sports information and news coverage in campuses. Third, online sports information not only includes wonderful performances and sports events, but also has physical education videos, which contains instructional videos in all aspects such as entertainment and fitness, and plays a good guiding role in the training of college students' sports skills. Fourth, online sports information has characteristics like interactive sharability and live broadcasting, enabling college students to watch live sports event videos, share sports information in time, and exchange sports information. 


\section{B. The Relationship between Online Media and Sports Information}

According to the survey conducted by the China Internet Network Information Center in 2015, the number of college student netizens in China has exceeded $90 \%$. The online media has spread widely on university campuses and become the main channel for college students to obtain sports information. Meanwhile, with the rapid development of Internet information technology, the status of online media in the channel of sports information dissemination will be further enhanced. The main relationships between online media and sports information are as follows.

\section{1) Online media speeds up the dissemination of sports} information and enhances the spread of sports information.

Network media plays a good role in promoting the dissemination of sports information [3], which is mainly manifested in these aspects: firstly, online media can effectively reduce the distance between the social mass and sports activities; secondly, online media accelerates the dissemination of sports information and enhances the spread of sports information, the coverage of online sports information becoming more extensive; thirdly, online sports information can better attract social attention and establish a new image for modern sports activities, thereby promoting the construction of sports culture; finally, network media can better coordinate the relationship between sports and commercial advertising, promoting sports competition to marketization.

2) Sports information is indispensable in news content of the online media.

At present, our society is in an age of information explosion; sports culture has spread widely, and sports information occupies a central place in the online media. On the other hand, the wide dissemination of sports information can not be separated from the promotion of online media. Network media has integrated sports culture with business culture and political culture; sports have become a popular phenomenon in the current society, affecting the overall status of the country and the development of social spiritual civilization.

3) Online media has promoted the development of sports.

In the traditional media era, the development of sports in our country was very slow, and its development scale was far inferior to that of the western developed countries. Since the Beijing Olympic Games was held in 2008, the extensive spread of China's sports by the online media has greatly promoted the development of sports in our country [4]. It has also expanded the scale of sports development and greatly enhanced China's international reputation of sports. A variety of wonderful sports programs and events can be broadcast live and rebroadcast through the online media to meet the individual needs of audience, thereby achieving real-time interactive review of audience to break the traditional time and space constraints, as well as audience can gather in the virtual platform to share sports information. Therefore, online sports information can attract members all over the world, exert a great influence on their sports awareness and behavior, and simultaneously promote the wide spread of the modern sports culture.

\section{INFLUENCE OF ONLINE SPORTS INFORMATION ON} COLLEGE STUDENTS' SPORTS CONSCIOUSNESS AND BEHAVIOR

\section{A. The Stimulation of College Students' Sports Consciousness and the Change of Passivity into Initiative}

Sports awareness is very important for college students to participate in physical exercise. Only with sports awareness can they be enthusiastic about physical exercise and actively participate in it. If students have negative sports awareness, they will lose interest in physical exercise, which is not conducive for college students to take the initiative to participate in physical exercise and is very passive for them to build the body. The formation of college students' sports awareness is influenced not only by individual subjective factors, but also by the factors such as society, family and school. At present, the speed of dissemination of online sports information is getting faster and faster, all kinds of online sports information are constantly updated, and college students gradually take the initiative to search sports information online to understand their needs of sports information, gradually changing their mentality and sports awareness from "the passive" to "the active". What's more, college students are very concerned about the NBA events as well as the World Cup, and watching these sports videos can inspire their morale so that they are passionate about physical exercise and gradually go out of the dormitory or classroom. Actively carry out sports activities. Online sports information has widely spread, so understanding of sports information for college students is longer confined to the physical education class. College students can follow their own hobbies to focus on related sports, from which they learn and understand the relevant sports skills to make themselves continue to pursue a higher level of sports life. In the course of browsing online sports information, college students can constantly hone their own volitional quality, which plays an important role in shaping the personality of college students and lays a good foundation for their future life and development [5].

\section{B. Online Sports Information Making College Students' Sports Values Change from the Single to the Diversification.}

Sports values mainly refer to the viewpoints formed by people's understanding of sports culture in sports activities and also reveal their needs for sports culture, simultaneously intensively reflecting people's sports awareness. Sports activities must be consistent with sports values in order to meet people's demand for sports activities, which also determines the diversity and hierarchy of sports values. At present, among college students sports activities, physical education holds a principal status. Mandatory physical education activities enable students to master a professional sports skills in order to handle exams and improve physical fitness; test scores are an important criterion for students' mastery of this sporting skill, students' physique situations also the only measure of a student's health. Under this kind of sports environment, college students' sports values are very single, their cognition on sports culture superficial. With the widespread dissemination of online sports information, channels for college students to contact with sports information and knowledge have been greatly expanded. The students differ in interests, hobbies, ages 
and genders, so there are big differences in the choice of sports activities. A great variety of online sports information provides college students with more choices of sports and fitness programs, which will lead to a change of college students' sports values from the single to the diversification; the main aim is not exams and physical fitness any more but entertainment, adjustment of life pressure, promotion of their own personality development, and achievement of fun. Online sports information can help college students to form a clear sense of motivation to exercise according to their own planning.

\section{Influence of Online Sports Information on College Students' Sports Behavior}

Sports behavior mainly refers to behavior consciously produced by people using various methods to meet all kinds of sports activities. Sports behavior influenced by social culture has a close relationship with people's innermost feelings. At present, physical exercise dominates other college students' sports behavior so as to create a strong physique. Physical exercise is a physical education lesson every week. This kind of sports behavior is rather single, which is not conducive to students' integration into a diversified sports environment. The wide dissemination of online sports information will bring many diversified sports activities to students such as sports behavior of leisure, health, social contact, morality and career choices. In college students' sports life, extracurricular sports activities are an indispensable part. Only by enriching extracurricular sports activities can the diversified development of college sports life be promoted. In college students' physical education [6], the teaching content is very old, backward and can not keep pace with the times. At present, the popular sports activities such as yoga, hip-hop and roller skating are not carried out in college sports, but in order to enrich college sports, these activities must be vigorously developed. Online sports information and physical education are complementary. Watching various videos of physical education and events can meet not only students' hobbies but also their diverse sports needs, and make them spontaneously organize all kinds of sports clubs or associations [7]. Carrying out a variety of sports competitions and commercial performances through drawing social sponsorships to mobilize students' enthusiasm in sports and make their sports behave diversified. All of the above can not only enrich students' after-school life, promote exchange and contact between students and the society, enhance students' understanding of physical exercise, but also enhance physical fitness and lay a good foundation for future careers [8-9].

\section{CONCLUSION}

With the rapid development of Internet information technology, online media has become a main media form of the current sports information dissemination and has spread widely in university campus, which owns a great impact on college students' sports awareness and behavior. Online sports information can stimulate college students' sports awareness, make them take the initiative to participate in physical exercise, and enable them to change their sports values from the single to the diversification, which is conducive to the development of college students' personality, enriches their' sports behavior, and plays an important role in growth of college students' physical and mental health.

\section{REFERENCES}

[1] Liu Chengwei. The Impact of Mass Media of Sports Information on College Students' Sports Awareness [J]. Shandong Sports Science and Technology, 2013,03: 105-108.

[2] Zhang Lei.Investigation and Research on the Needs of College Students in Henan Province for the Internet Media Sports Information [J]. Shaolin and Taiji (Zhongzhou Sports), 2012,05: 50-52.

[3] Ai Xiaoping.Effects of Online Sports Information on College Students' Sports Lifestyle [J]. Management \& Technology of SME, 2012,11: 263.

[4] Chen Haijiao, Guo Jianwei. Investigation and Research on the Current Situation of Computer Network Security Consciousness of College Students in PE Institutes-A Case Study of Wuhan Institute of Physical Education $[\mathrm{J}]$. Pioneering with Science and Technology Monthly, 2011,07: 98-100.

[5] Yang Na. Research on College Students' Sports Behavior in Internet Information Age $[\mathrm{J}]$. The Guide of Science \& Education (middle), 2011,11: 204-205.

[6] Du Guoru. Study on Health Guidance of College Students' Demand of Sports Consumption - A Case Study of Some Universities in Jiangxi Province $[\mathrm{J}]$. China School Physical Education (Higher Education), 2014,05: 7-13.

[7] Xuan Daling. The Impact of Mass Media Sports Information on College Students [J]. News Front, 2015,03: 157-158.

[8] Yu Lin. Influence of Media Sports Information on College Students' Participation in Physical Activities [J]. Contemporary Sports Technology, 2015,25: $223+225$.

[9] Gu Chunxian, He Wentao. Research on the Media Contact of Chinese College Students Sports Information in New Period [J]. Journal of Southwest Guizhou Teachers College for Nationalities, 2015,05: 113116. 